\title{
Dam function rules based on brown trout flow requirements: design of environmental flow regimes in regulated streams
}

\author{
C. Alonso-González · J. Gortázar • \\ D. Baeza Sanz • D. García de Jalón
}

\begin{abstract}
The operation of small hydroelectric dams built on mountain streams induce changes in stream flow regimes that are manifested not only in the intensity of flow events, but also in the variability and frequency of high- and low-flow episodes. Former studies have shown the influence of flow variability upon the dynamics of a resident brown trout population, especially that related to the stream flow regime during spawning, incubation and emerging periods. As these life-stages are known to determine the population dynamics in further ages, stream flow variability appears to be a major influence on the regulation of a wild brown trout
\end{abstract}

C. Alonso-González

Sciences Faculty, Catholic University of Ávila, Avila, Spain

C. Alonso-González · J. Gortázar · D. Baeza Sanz •

D. García de Jalón

Laboratory of Hydrobiology, Technical College of Forest

Engineering, Technical University of Madrid, Madrid,

Spain

C. Alonso-González ( $\triangle$ )

Laboratorio de Hidrobiología, Dpto. Ingeniería Forestal, E.T.S.I. Montes, Universidad Politécnica de Madrid, Av. Ramiro de Maeztu s/n, Ciudad Universitaria, Madrid 28040, Spain

e-mail: carlosalonso@ecohidraulica.com population. Thus, mean flow discharge should not be the only parameter taken into account when establishing ecological flow regimes to support rehabilitation of degraded trout populations in mountain streams. Ecological stream flow regime characteristics are proposed as a basis for the design of environmental flow regimes in mountain reaches downstream of hydroelectric or water supply dams. Case studies were conducted in a high mountain basin in Central Spain (River Tormes) for a period of 5 years showing that relationship between duration and frequency of high and low flow episodes during egg incubation could be linked to young-of-the-year recruitment and quantified in terms of flow management units. Duration and frequency of flow discharges could be manipulated so as to create favourable hydrological conditions for restoring sustainable populations of brown trout in rivers affected by flow regulation

Keywords Regulated rivers - Flow regime . Environmental flows - Population dynamics . Hydrological requirements . Brown trout

\section{Introduction}

In unfavourable habitats with low population densities, major changes in salmonid population seem to be due to density-independent factors (Elliott, 1994). Hence, the effects of stream flow regimes on 
population variables should be easier to detect in a mountain watershed with a continental climate and high intra- and inter-annual variability of hydrological regimes. Such an unpredictable flow regime may regulate a trout population through its influence on the survival and growth of individuals in each cohort (Baeza Sanz \& García de Jalón, 1997).

The stream flow regime, comprising its mean values (affecting the carrying capacity and suitable habitat) as well as its extreme values (floods and droughts), is known to act as an important abiotic factor in the limitation of brown trout populations. The limitation and control of population parameters produced by catastrophic stream flow events has been thoroughly studied by several authors. Extreme minimum values of flow regimes reflect the intensity of droughts, and can affect individual growth (Weatherley et al., 1991), density (Elliott et al., 1997; Bell et al., 2000) and shelter availability by brown trout (Elliott, 2000). Similarly, extreme maximum flows appear to have an important role in riverine fish population control. Thus, floods during snowmelt periods govern survival (Jensen \& Johnsen, 1999) and recruitment of salmonid fishes (Latterell et al., 1998). All these studies focused on the performance of each life-stage during the first year of life of each cohort. (Cattanéo et al., 2002). In the present study, annual flow regime data were studied in the context of three critical periods: (1) spawning until emergence of fry, (2) emergence until July of the first summer of life, and (3) the 12 months prior to the date when sampling campaigns began.

Since water demand for human uses increases dayby-day, a growing number of rivers, streams and torrents are controlled and their flows modified (García de Jalón, 2003). The construction of water supply structures and hydropower devices implies instream flow regulation, and their use alters natural flow regimes. Poff et al. (1997) have shown the need to maintain or restore the natural range of variation of hydrological regimes as a fundamental element for protecting fluvial ecosystem integrity. For this purpose, they have described key components of river regimes that regulate physical and biological processes in fluvial ecosystems. These are generally considered to be: magnitude, frequency, duration, timing and rate of change (Poff \& Ward, 1989; Richter et al., 1996; Olden \& Poff, 2003). River flow regimes and their relevant events can be described by hydrological indices derived from these components, which must adequately represent the main facets of the regime and the events that determine the biological functioning, geomorphologic processes, and the transportation of nutrients and sediment.

In summary, the general aim of this work is to find out the effects of natural variability of stream flow regimes on the principal parameters of the dynamics of a brown trout population, identifying those components and hydrological indices that significantly affect the main phases of the trout life cycle. These results can help us establish some easy-to-adopt rules for dam functioning and flow releases that will fit brown trout flow requirements.

\section{Study area}

The study area (mean altitude $1,200 \mathrm{~m}$; area ca. $900 \mathrm{~km}^{2}$ ) comprises the upper basin of river Tormes, in the Northern slope of Sierra de Gredos mountains, in Central Spain $\left(40^{\circ} 20^{\prime} \mathrm{N} ; 5^{\circ} 42^{\prime} \mathrm{W}\right)$. The location of the study basin in a high mountain continental climate area means that rainfall and temperature regimes are highly variable, both within years and between years. Mean air temperatures range intraannually between -1 and $18^{\circ} \mathrm{C}$, and annual rainfall regime (mean value ca. $850 \mathrm{~mm}$ ) has a marked minimum in summer (ca. $20 \mathrm{~mm}$ ) and local maxima in autumn-winter. Geologically, the study basin is located in a great batholith with relatively uniform mineralogical granite composition. The vegetation structure of the basin comprises a series of extended grazing lands with Scots pine (Pinus sylvestris) forests and meadows near the lowest points of the slopes.

The river Tormes (tributary of river Duero) flows through a v-shaped basin for ca. $40 \mathrm{~km}$ until it reaches the limit of the study area.

The study watershed supports a medium-sized population (mean biomass $5.4 \mathrm{~g} . \mathrm{m}^{-2}$ ) of brown trout (Salmo trutta L.), and cohabiting cyprinid species, Squalius carolitertii Doadrio and Chondrostoma duriense Coelho, $\left(2.4 \mathrm{~g} \cdot \mathrm{m}^{-2}\right)$. Water is mainly acidic or neutral $(6.6<\mathrm{pH}<7.5)$ with an invertebrate community exhibiting high biotic integrity (AlbaTercedor \& Sánchez-Ortega, 1988).

The mean annual flow varies from $1.8 \mathrm{~m}^{3} \cdot \mathrm{s}^{-1}$ in the upper reaches of the river Tormes to $55.8 \mathrm{~m}^{3} \cdot \mathrm{s}^{-1}$ 
in its lower reach in the study basin. The studied streams do not have any significant flow regulation structures, and thus the flows observed were more or less natural. Flow regime in the studied area has a great variability: Temporally (because of its Mediterranean precipitation regime) and spatially (because of its topography). The stream network is composed of a main river with relatively low slope, and many very steep tributaries coming from high mountains. This fluvial morphology causes flushing flow conditions, especially at snow-melt episodes.

\section{Methods}

Population parameters

Fourteen sampling stations were selected in the study ranging from 1,010 to $1,470 \mathrm{~m}$ in altitude, seven in the river Tormes and seven in tributaries maximizing representativeness of the watershed. Five annual survey campaigns were carried out in July during a five-year period (1998-2002) in every sampling station, accounting for a total of 70 sampling occasions. Figure 1 shows the location of the sampling sites and the gauging stations where data were obtained.

During each survey campaign, three-pass removal electrofishing was conducted in each sampling site, which was enclosed using stop-nets. Fork lengths (L) to the nearest $\mathrm{mm}$. and wet weights $(\mathrm{W})$ to the nearest $0.1 \mathrm{~g}$ were measured in every captured fish. Scales were taken from a stratified sub sample of $25 \%$ of captured trout for further age determination.

Densities (D) were estimated by the Maximum Weighted Likelihood method (Carle \& Strub, 1978). Age was determined for each age class by means of a combination of scale reading and length frequency analysis (Bhattacharya 1967 modified by Pauly \& Caddy, 1985). Emergence period of each cohort was estimated by modelling the growth of the captured $0+$ class individuals between their emergence and the date of capture by taking into account the stream temperature regime during this period (Baglinière \& Maisse, 1990; Alonso-González, 2003). Spawning season was determined: (1) by subtracting $440^{\circ} \mathrm{C}$.days from the emergence date and (2) by the observation of spawners during each season.
Loss rate ( $\mathrm{Z})$ of each cohort was determined as the percentage reduction of each cohort between two consecutive annual sampling campaigns. Growth rate (G) was estimated by the difference of the natural logarithm of mean fork lengths observed in the same cohort in two consecutive years. Fulton condition factor $(\mathrm{K})$ was also calculated for each individual.

Population variables were $\ln (x+1)$ transformed in order to normalise their distribution.

\section{Stream flow regime}

Two series of data each from a gauging station (Duero Basin Water Authority-C. H. Duero) have been employed in this work.

(1) mean daily flow data (to the nearest $0.001 \mathrm{~m}^{3} \cdot \mathrm{s}^{-1}$ ) from station $\mathrm{n}^{\circ} 02006$ in the headwaters (altitude $1377 \mathrm{~m}$; catchment area $88 \mathrm{~km}^{2}$ ), and

(2) mean monthly flow data (to the nearest $\mathrm{hm} 3$ ) from a 54-year historical series (1931-1990) in gauging stations $\mathrm{n}^{\circ} 02006$ (see above characteristics) and $n^{\circ} 020135$ in the lower reaches, $4.2 \mathrm{~km}$ downstream the exit of the study basin (altitude $976 \mathrm{~m}$; catchment area $900 \mathrm{~km}^{2}$ ).

Annual stream flow regimes in the fourteen sampling reaches were estimated by flow standardised data from both gauging stations, adjusted in a linear model $\left(\mathrm{R}^{2}=0.93\right)$ that relates flow regimes to catchment area and mean catchment altitude (Alonso-González, 2003). Transferability of flow data from both gauging stations was supported by: (1) the similarity $\left(\mathrm{R}^{2}=0.74\right)$ of downpour peak distributions recorded in two meteorological stations INM adjacent to both gauging stations; and (2) the homogeneous geology of the basin, indicative of a similar hydrologic response to rainfall regimes in separated points.

Five variables were determined for every period in which years were divided according to the abovementioned first year of life stages (see 3.1. Population parameters): maximum $\left(\mathrm{Q}_{\max }\right)$, mean $\left(\mathrm{Q}_{\mathrm{med}}\right)$ and minimum $\left(Q_{\min }\right)$ daily flow, the number of days in which maximum flow was higher than the value of $75 \%$ of the data series $\left(\mathrm{Q}_{\text {perc } 75}\right)$ and lower than the $25 \%$ of the data series $\left(Q_{\text {perc25 }}\right)$. The first three variables represent a parametric description of flow regimes, while the last two represent a non-parametric description of the distribution of daily flows. Thus, annual flow, intensity of floods and droughts, and 


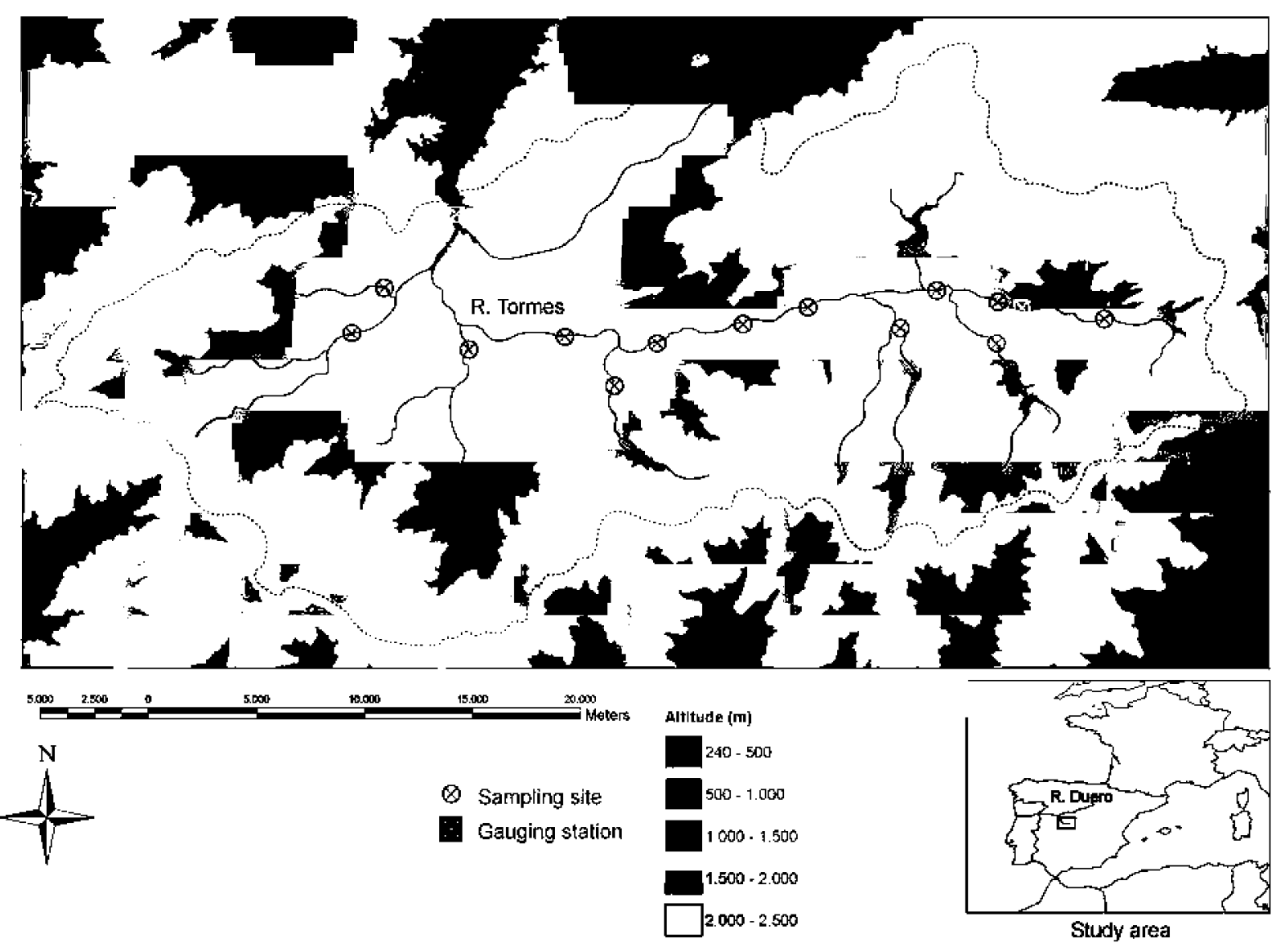

Fig. 1 Sampling sites and gauging stations in river Tormes basin employed in the study

frequency of both events, were considered. These rather simple metrics were chosen instead of other more specific flow variables, such as those selected by Olden \& Poff (2003), in order to give useful easyto-adopt measures on dam functioning. The amount of variability of population parameters that is explained by such specific metrics is analysed indepth by Alonso-González, (2003).

Hydrological variables were also $\ln (x+1)$ transformed, so as to normalise their distribution.

\section{Statistical analysis}

It can be assumed that all individuals captured in the sampling stations belong to a single brown trout population as there are no barriers to free movement of individuals within the catchment and extreme flow conditions stimulate frequent fish movements (droughts make adults go downstream searching for pools in the main channel and floods flush fry downstream). Besides, taking into account the low abundance of brown trout in sites downstream the study basin (Alonso-González \& García de Jalón, 1999), there appears to be no significant emigration.

Berryman (2002) defines population as "a group of individuals of the same species that live together in an area of sufficient size to permit normal dispersal and/or migration behaviour and in which numerical changes are largely determined by birth and death processes", therefore, population changes should not be dependent on movement, but, rather, on the processes of reproduction and survival alone. In other words, when studying the dynamics of a whole population, the study area must be large enough for the emigration and immigration rates to be negligible or, at least, roughly balanced.

According to this, it can be expected that the general trends of the parameters of the whole population can be characterised by between years variation of central tendency estimates, such as mean 
values of all sampling sites. For this reason, electrofishing survey data from all stations were synthesized, so as to quantify yearly variations of the whole population. Prior to statistical analyses, Shapiro-Wilks normality tests were conducted, and the existence of statistically significant differences among the means, medians and distributions of the fourteen values of each annual campaign were verified in order to check whether the range of values observed during the study period was significant.

Linear relationships between every combination of population and hydrological variable were analysed by a correlation matrix. Relationships were considered ecologically significant when matching the three following criteria: (1) r-Pearson correlation coefficient absolute value higher than 0.9 , (2) number of pairs of data values used to compute each coefficient $\geq 4$, and (3) $P$-values below 0.05 , which indicate statistically significant non-zero correlations at the 95\% confidence level.

\section{Results}

The distributions of values observed for each state variable in all sampling stations during the study period are presented in Fig. 2.

A summary of the values observed for each population parameter obtained from the state variables shown in Fig. 2 is presented in Table 1. Mean values and standard deviations between years are shown for each population parameter (loss rate, growth rate and condition factor) in order to evaluate the population variability between years.

Table 2 summarises the values observed in the hydrological variables during the studied years.

Which flow regime traits were controlling population characteristics was evaluated by an analysis of all possible relationships between them. Only four significant correlations were observed that fulfiled the criteria Selected correlations are shown in Table 3.

Regressions showing the proportion of variability of population variables explained by flow metrics above mentioned are represented in Fig. 3.

\section{Discussion}

There were four significant relationships between pairs of hydrological and population variables two of which have obvious explanations, while the other two are not so easy to explain. For instance, the correlation between mean annual flow $\left(Q_{\text {meanyear }}\right)$ and the density of $0+$ trout in summer may be explained only assuming that the mean annual flow picks up a high flow winter which might have the effect of washing out eggs and larvae. However, in that case, the noncorrelation with maximum daily flows $\left(Q_{\max }\right)$ is surprising.

Furthermore, the correlation between mean fork length of $1+$ age class trout to the frequency of days with low flow $\left(\mathrm{Q}_{\text {perc25EJul }}\right)$ in late spring and early summer has no direct explanation. However, this may be because low spring and summer flows result in sub-optimal conditions for growth of $1+$ fish (density effects) or that these conditions are associated with higher water temperatures which may be sub-optimal for growth. Nevertheless, much more work has to be conducted in order to establish possible cause-effect relationship.

The other two correlations detected give useful information on the response of a salmonid population to flow variations.

The strong negative correlation between duration of floods during the incubation period $\left(\mathrm{Q}_{\text {perc75Inc }}\right)$ and recruitment of fry $\left(\mathrm{D}_{\mathrm{O}_{+}}\right)$suggests that the longer the period with high flow conditions during incubation, the lower the recruitment of young-of-the-year. Conversely and somewhat surprisingly, no significant correlation was found between recruitment and flood intensity, although floods over the $75 \%$, and one over the $90 \%$ affected two years during the study period of the last 60 years. Many authors have found negative relationship between discharge intensity and recruitment of fry, Jensen \& Johnsen (1999) linked intensity of discharge during the emergence of a cohort with a reduction on the cohort strength, as does Spina (2001) who detects a negative correlation between flood peaks during incubation and the cohort strength. Cattanéo et al. (2002) found that $0+$ trout density was strongly and negatively related to the discharge rate during the emergence period, and reports that other authors found similar effects in salmonid fishes. The number of studies drawing similar conclusions suggest that intensity of floods during incubation and emergence are very important factors determining trout recruitment. However there is little evidence from the literature concerning the effect of number of days with high flow conditions on annual recruitment. 
Fig. 2 Values of the population variables observed in the fourteen sampling sites during the study period, where:

Biomass is trout biomass (g.m ${ }^{-2}$ ); Dens density (individual. $\mathrm{m}^{-2}$ ); Length mean fork length ( $\mathrm{mm}$ ) and Weight mean wet weight (g) of captured trouts
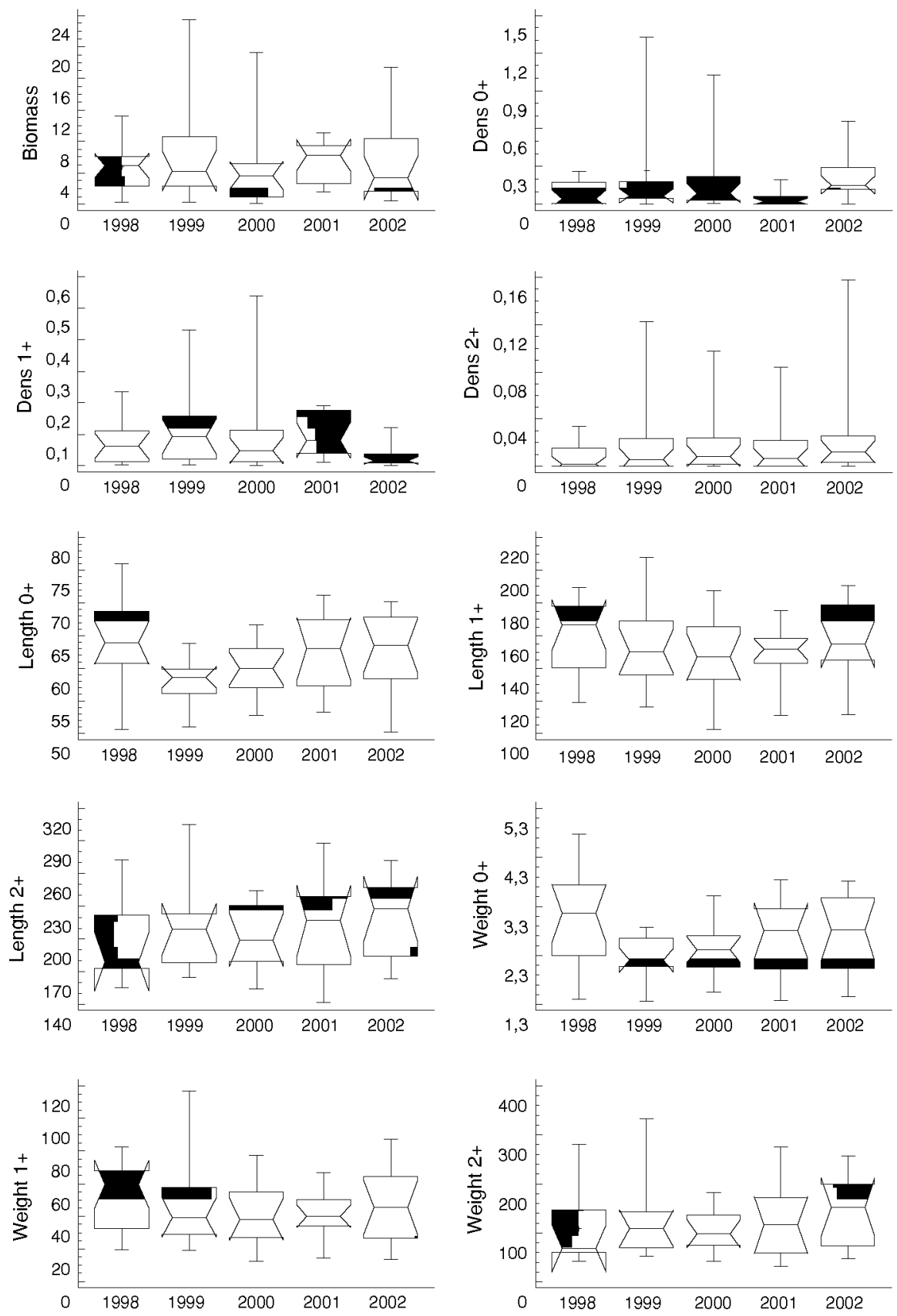

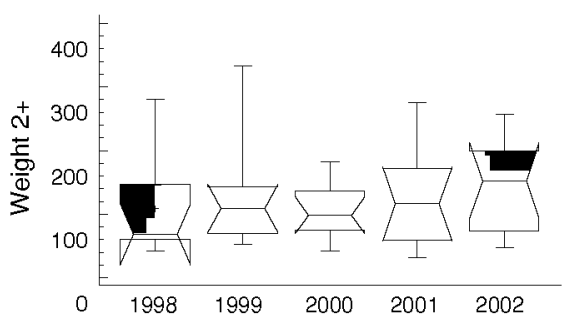

This effect can be due to the damage occasioned in redds when occurring repeated flooding episodes during incubation, or due to the time that redds spend in different hydraulic conditions than those chosen by spawners during spawning season.

Some better understanding of the causes of this correlation can be achieved when taking into account some results observed by the authors in another work
(Alonso-González, 2003). A significant negative correlation ( $\mathrm{r}$-Pearson $=-0,94 ; 95 \%$ confidence level) was found between the number of days during the incubation period with flows higher than the mean value of daily flow during spawning season for a 50 -year series of data in the same study area. This fact may represent an evidence to support the second explanation. 
Table 1 Mean values (Mean) and standard deviations between years (SD) of the population parameters determined from state variables shown in Fig. 2, in the 14 sampling stations of river Tormes brown trout population

\begin{tabular}{lrll}
\hline & Z & G & K \\
\hline Age class 0+ & & & \\
$\quad$ Mean & -0.76 & 0.88 & 1.11 \\
SD & 1.14 & 0.03 & 0.03 \\
Age class 1+ & & & \\
Mean & 0.73 & 0.36 & 1.18 \\
SD & 0.09 & 0.05 & 0.04 \\
Age class 2+ & & & \\
$\quad$ Mean & & & 1.21 \\
SD & & & 0.02 \\
\hline
\end{tabular}

Where, Z-loss rate $\left(\right.$ year $\left.^{-1}\right)$; G-growth rate $\left(\right.$ year $^{-1}$ ); and $\mathrm{K}$-condition factor $\left(10^{5} \mathrm{~g} \cdot \mathrm{mm}^{-3}\right)$ of each age class

Table 2 Mean values (Mean) and standard deviations between years (SD) of the hydrological variables estimated in the 14 sampling stations of river Tormes

\begin{tabular}{llllll}
\hline & $Q_{\text {maxInc }}$ & $Q_{\text {medInc }}$ & $Q_{\text {minInc }}$ & $Q_{\text {perc75Inc }}$ & $Q_{\text {perc25Inc }}$ \\
\hline Mean & 28.42 & 5.28 & 1.69 & 56.75 & 10.57 \\
SD & 20.84 & 3.21 & 1.00 & 13.72 & 6.81 \\
\hline & $Q_{\text {maxEJul }}$ & $Q_{\text {medEJul }}$ & $Q_{\text {minEJul }}$ & $Q_{\text {perc75EJul }}$ & $Q_{\text {perc25EJul }}$ \\
\hline Mean & 14.03 & 3.26 & 0.36 & 43.00 & 25.71 \\
SD & 10.29 & 1.49 & 0.31 & 14.23 & 2.92 \\
\hline & $Q_{\text {maxyear }}$ & $Q_{\text {medyear }}$ & $Q_{\text {minyear }}$ & $Q_{\text {perc75year }}$ & $Q_{\text {perc25year }}$ \\
\hline Mean & 35.44 & 3.09 & 0.03 & 90.66 & 108.50 \\
SD & 29.84 & 1.50 & 0.04 & 14.23 & 26.81 \\
\hline
\end{tabular}

Where: $\mathrm{Q}_{\max }$-maximum daily flow; $\mathrm{Q}_{\text {med }}$ mean annual flow; and $Q_{\text {min }}-$ minimum daily flow $\left(\mathrm{m}^{3} \cdot \mathrm{s}^{-1}\right)$; and $Q_{\text {perc75 }}$ and

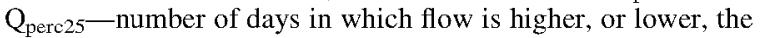
$75 \%$ and $25 \%$ of the temporal series, respectively. Every variable is determined for each period: Incubation (Inc); emergence to 1 st summer (EJul); and the year immediately before sampling campaign (year)

In the present study, a significant negative correlation was also found between mean length of fry and the number of low flow days during incubation. This interesting correlation can reinforce the former explanation, as it can be due to an effect of low temperatures on eggs laid in a redd when it is affected by a reduction in the water column depth. A lower flow leads to a shallower water column over the redds and thus a higher influence of wintry air temperature regimes on the water temperature in the redd and,
Table 3 Population and hydrological variables between which a strong linear relationship was detected, correlation coefficients (r-Pearson) and statistical significance ( $P$-value)

\begin{tabular}{llll}
\hline Population var. & Hydrological var. & r-Pearson & $P$-value \\
\hline D0+ & $Q_{\text {perc75Inc }}$ & -0.9425 & 0.0164 \\
D0+ & Qmeanyear & -0.9568 & 0.0432 \\
L0+ & $Q_{\text {perc25Inc }}$ & -0.9078 & 0.0332 \\
L1+ & $Q_{\text {perc25EJul }}$ & -0.9649 & 0.0078 \\
\hline
\end{tabular}

$\mathrm{D}_{0+}$ density (individual. $\mathrm{m}^{-2}$ ), $\mathrm{Li}+$ mean fork length $(\mathrm{mm})$; $\mathrm{Q}_{\text {perc75Inc }}$ number of days in which flow is higher the $75 \%$ of the incubation period; $Q_{\text {medyear }}$ mean annual flow

consequently, around the eggs or larvae. A repeated or long-lasting occurrence of these circumstances can lead eggs or larvae to a slower development and a less efficient use of energy reserves in the yolk.

As no correlation between intensity and recruitment has been detected, moderated but repeated or long-lasting floods could be able to affect annual recruitment at least as markedly as big isolated spates. Moreover, this observed effect could become a useful basis from which to explain the absence of effects on the recruitment of a severe spate in a brown trout population in the North of Spain, reported by Lobón-Cerviá (1996). Thus, a big isolated spate could not be effective in significantly reducing recruitment, but frequent repeated or long-lasting moderated floods could. It may happens that the flow threshold that produces conditions damaging to recruitment lies well below the $75 \%$ flow, meaning that the very high flow events don't cause any more damage than moderate floods, and the key issue should rely more in the flood duration.

An explanation of this phenomenon may be linked to the process of spawning site selection by adult salmonids. The parent fish are thought to seek out particular flow conditions that are optimal for egg deposition, incubation hatching and emergence. If flow conditions during the incubation period differ greatly from those pertaining when eggs were laid for long periods, then reduced survival of eggs and alevins might be expected. The location of most spawning habitats in the upper reaches (with flood period shorter) of the rivers can explain the lack of influence of the intensity of big spates on the recruitment, while the effects of spates on fish habitat are expected to be stronger in the lower reaches of the study basin (with floods lasting longer). 
Fig. 3 Regression analyses and proportion of variability $\left(\mathrm{R}^{2}\right)$ of population variables explained by flow metrics by means of linear models
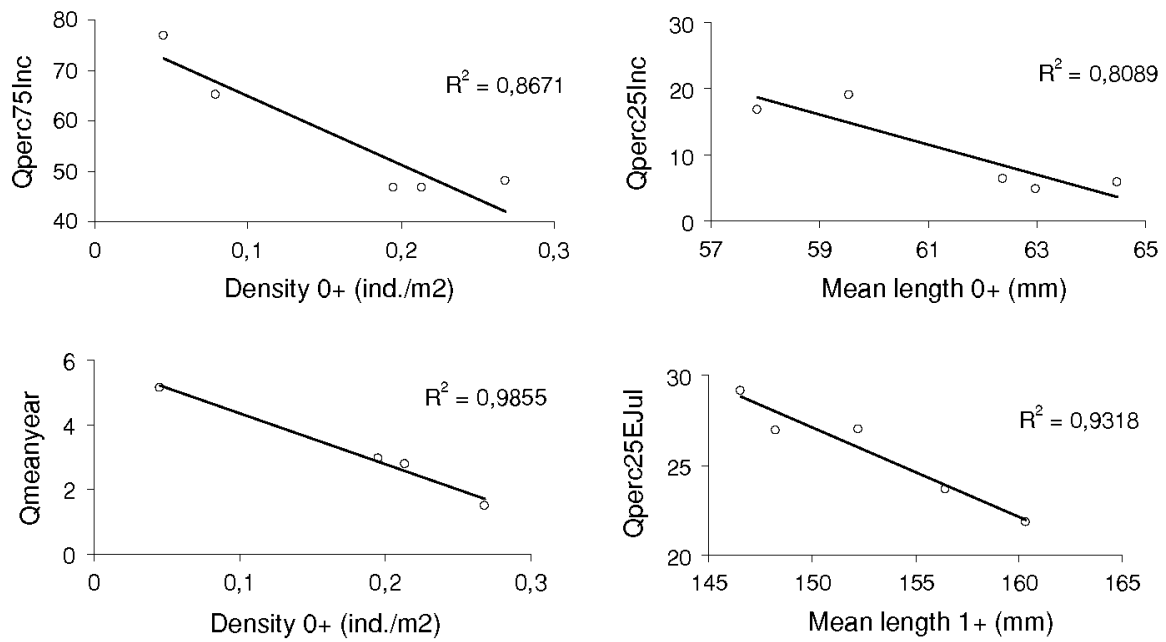

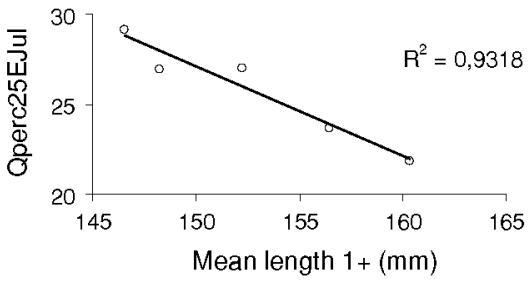

The application of this conclusion to populations inhabiting rivers affected by regulated flows and hydropeaking episodes justifies further research in this direction.

Nonetheless, general criteria can be given in order to assure, at least to some extent, the integrity of the dynamics of a wild brown trout population. Using linear models shown in Fig. 3, threshold values of independent flow variables can be chosen in order to achieve a certain value for each dependant population variable. Therefore, some guidelines on flow regime conditions that have to be respected downstream hydroelectric devices or water supply dams might be:

- Not to generate floods over the 3rd quartile $\left(Q_{\text {perc75Inc }}\right)$ of a five-year mean daily flow series during incubation for more than 55 days;

- nor to retain water flow lower than the 1 st quartile $\left(Q_{\text {perc25Inc }}\right)$ of the same flow data series for more than 10 days during the same period;

- not to create droughts below first quartile of the same flow data series for more than 25 days during spring $\left(\mathrm{Q}_{\text {perc25EJul }}\right)$.

These guidelines should be considered as provisional rules for dam function while more research on thresholds is conducted, but they can serve as an example of how population dynamics can give us a tool to design environmental flow regimes in regulated streams.

Figure 4 illustrates the above instructions as examples of bad and good practices on functioning hydroelectric devices or water supply dams. Instream flows are analyzed and monitored to detect if its fluctuations are under the mentioned thresholds.

\section{Conclusions}

The literature includes a number of papers that measure the degree of deviation from the natural state due to a particular intervention, such as a reservoir or a water transfer; a very common situation in Spain (García de Jalón et al., 1992; Ibáñez et al., 1996). On the other hand, research is also being carried out into the relationships between particular flow regimes and the biological communities that inhabit the river stretches where these regimes exist. Such studies serve to establish how far regimes can be deviated from their natural state without irreversibly altering the dynamics of the fluvial environment, maintaining the natural biodiversity, and the fluvial habitat heterogeneity. For this purpose is very important to identify those hydrologic parameters with a suitable biological relevance.

The frequency and/or duration of drought and flood episodes seem to influence population dynamics more profoundly than does the intensity of severe extreme flow episodes. Now the challenge is to determine which processes govern influence of hydrological variables on recruitment: frequency, duration or both.

Design of specific flow operation margins can be used to adapt previously designed minimum stream flow regimes to hydrological requirements of every 

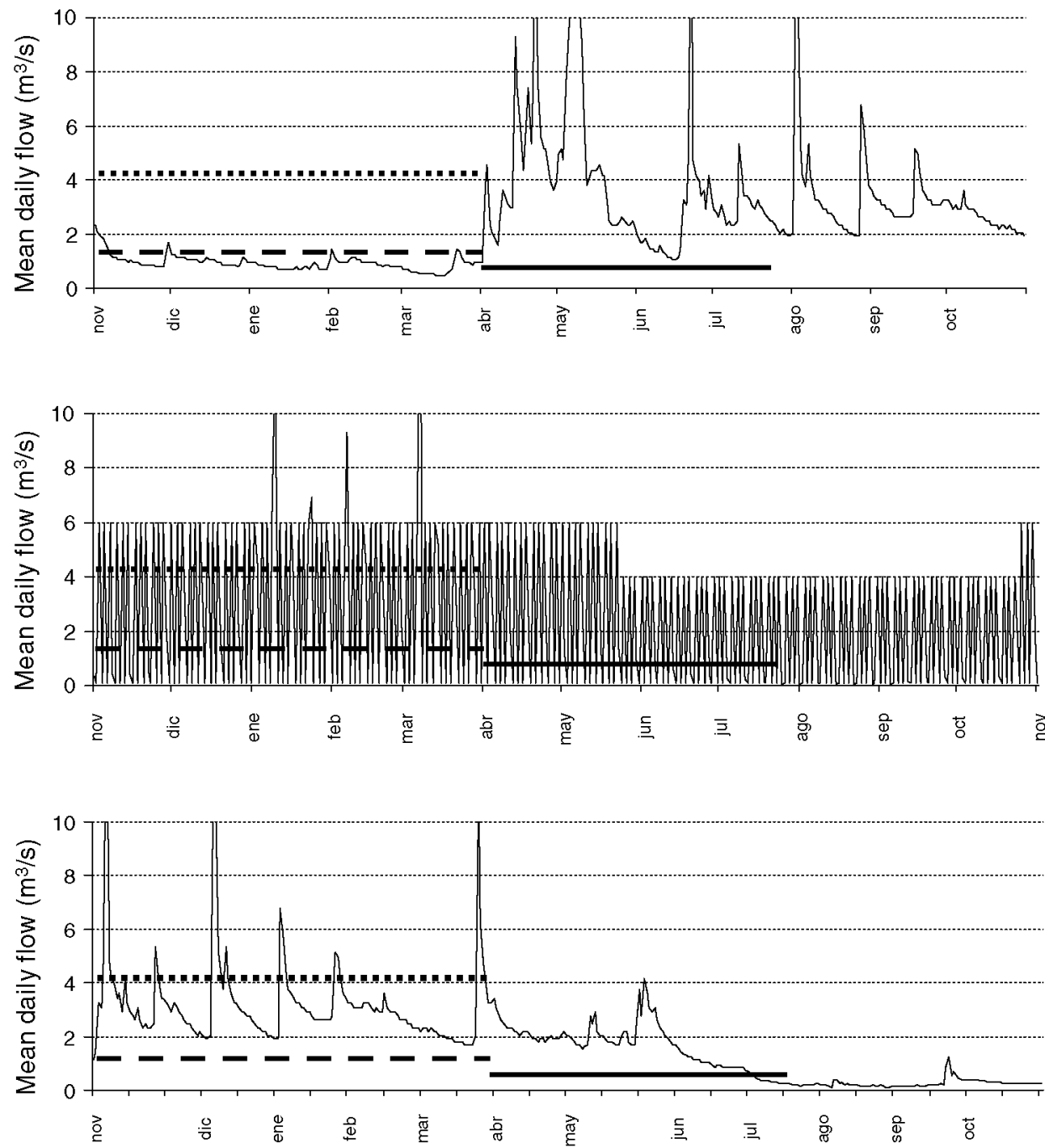

Fig. 4 Flow operation margins to observe brown trout population dynamics requirements in a Central Spain mountain reach: (a) Non acceptable water supply dam operation regime; (b) Non acceptable hydroelectric device operation regime; (c)

life stage of a particular species, and thus, to assure that processes which take place throughout the year can be completed without affecting significantly the species population dynamics.

Aknowledgements This study has been supported by Consejería de Medio Ambiente de Castilla y León (Regional Environmental Authority), and technical and managerial support is due to Emilio Roy Berroya and Félix López Moyano. We also thank the anonymous reviewers for helpful comments on the first manuscript, and the company Ecohidráulica S.L. (www.ecohidraulica.com) for sharing some equipments with us.
Correct operation margins. Dotted line $\mathrm{Q}_{\text {perc75Inc; }}$ broken line $\mathrm{Q}_{\text {perc25Inc; }}$; solid line $\mathrm{Q}_{\text {perc25EJul }}$ (percentiles of a five-year mean daily flow data series)

\section{References}

Alba-Tercedor, J. \& A. Sánchez-Ortega, 1988. Un método rápido y simple para evaluar la calidad biológica de las aguas corrientes basado en el de Hellawell (1978). Limnetica 4: 51-56.

Alonso-González, C., 2003. Caracterización de la dinámica de poblaciones de trucha común (Salmo trutta L.) en la cuenca alta del río Tormes y de los principales factores que influyen en ella. Tesis Doctoral, 2003. ETSI de Montes, Universidad Politécnica de Madrid, Madrid.

Alonso-González, C. \& D. García de Jalón, 1999. Estudio hidrobiológico de la cuenca del río Tormes en la provincia de Ávila. Junta de Castilla y León, Valladolid. 
Baeza Sanz, D. \& D. García de Jalón, 1997. Caracterización del régimen de caudales en ríos de la cuenca del Tajo atendiendo a criterios biológicos. Limnetica 13: 69-78.

Baglinière, J. L. \& G. Maisse, 1990. La croissance de la truite commune (Salmo trutta L.) sur le bassin du Scorff. Bulletin Français de la Pêche et de la Pisciculture 318: 89101.

Bell, V. A., J. M. Elliott \& R. J. Moore, 2000. Modelling the effects of drought on the population of brown trout in Black Brows Beck. Ecological Modelling 127: 141-159.

Berryman, A. A., 2002. Population: a central concept for ecology? Oikos 97: 439-442.

Carle, F. L. \& M. R. Strub, 1978. A new method for estimating population size from removal data. Biometrics 34: 621630.

Cattanéo, F., N. Lamouroux, P. Breil \& H. Capra, 2002. The influence of hydrological and biotic processes on brown trout (Salmo trutta) population dynamics. Canadian Journal of Fisheries and Aquatic Sciences 59: 12-22.

Elliott, J. M., 1994. Quantitative Ecology and the Brown Trout. Oxford University Press, Oxford, $286 \mathrm{pp}$.

Elliott, J. M., 2000. Pools as refugia for brown trout during two summer droughts: Trout responses to thermal and oxygen stress. Journal of Fish Biology 56: 938-948.

Elliott, J. M., M. A. Hurley \& J. A. Elliott, 1997. Variable effects of droughts on the density of a sea-trout Salmo trutta population over 30 years. Journal of Applied Ecology 34: 1229-1238.

García de Jalón, D., 2003. The Spanish experience in determining minimum flow regimes in regulated streams. Canadian Water Resources Journal 28: 185-198.

García de Jalón, D., M. Gonzalez del Tánago \& C. Casado, 1992. Ecology of regulated streams in Spain: An overview. Limnetica 8: 161-167.

Ibañez, C., N. Prat \& A. Canicio, 1996. Changes in the hydrology and sediment transport produced by large dams on the lower Ebro River and its estuary. Regulated Rivers 12: $51-62$.
Jensen, A. J. \& B. O. Johnsen, 1999. The functional relationship between peak spring floods and survival and growth of juvenile Atlantic Salmon (Salmo salar) and brown trout (Salmo trutta). Functional Ecology 13: 778-785.

Latterell, J. J., K. D. Fausch, C. Gowan \& S. C. Riley, 1998. Relationship of trout recruitment to snowmelt runoff flows and adult trout abundance in six Colorado mountain streams. Rivers 6: 240-250.

Lobón-Cerviá, J., 1996. Response of a stream fish assemblage to a severe spate in northern Spain. Transactions of the American Fisheries Society 125: 913-919.

Olden, J. D. \& N. L. Poff, 2003. Redundancy and choice of hydrologic indices for characterizing streamflow regimes. River Research and Applications 18.

Pauly, D. \& J. F. Caddy 1985. A modification of Bhattacharya's method for the analysis of mixtures of normal distributions. FAO Fisheries Circular 781: $16 \mathrm{pp}$.

Poff, N. L. \& J. V. Ward, 1989. Implications of stream-flow variability and predictability for lotic community structure: A regional analysis of streamflow patterns. Canadian Journal of Fisheries and Aquatic Sciences 46: 1805-1818.

Poff, N. L., J. D. Allan, M. B. Bain, J. R. Karr, K. L. Prestegaard, B. D. Richter, R. E. Sparls \& J. C. Stromberg, 1997. The natural flow regime. Bioscience 47: 769-784.

Richter, B. D., J. V. Baumgartner, J. Powell \& D. P. Braun, 1996. A method for assessing hydrologic alteration within ecosystems. Conservation Biology 10: 1163-1174.

Spina, A. P., 2001. Incubation discharge and aspects of brown trout population dynamics. Transactions of the American Fisheries Society 130: 322-327.

Weatherley, N. S., E. W. Campbell-Lendrum \& S. J. Ormerod 1991. The growth of brown trout (Salmo trutta) in mild winters and summer droughts in upland Wales: Model validation and preliminary predictions. Freshwater Biology 26: 121-131. 